\title{
HANDLING MULTI-LEVEL CLASSES IN THE CITY OF BATUMI Ivdit Diasamidze $^{1}$, Lali Tavadze ${ }^{2}$, Natia Katamadze ${ }^{3}$
}

\begin{abstract}
If we take into account the common teacher-centered or the one-book-fits-all approach, where the teacher is forced to focus on the middle level, many students at the top or bottom end of the language scale are left dissatisfied or demotivated. Once students are placed into a certain class they are regarded as being at much the same linguistic level in their foreign language, and a one-book-fits-all approach is often adopted in the classroom, where all students are required to work at the same pace and complete the tasks of the same difficulty. There are various scholarly approaches to the problem. This study aims to determine whether teachers are aware of possible techniques like differentiated work, dividing a class, letting students choose the task, other techniques, and what the frequency of their use is.

The survey was carried out among the teachers working at both higher education institutions and secondary schools to find out how often teachers refer to different techniques.

The results suggest that differentiated work requires much and thorough preparation on the part of a teacher, which becomes quite time-consuming at times. Therefore, teachers try to deal with mixed-level classes using mostly class division into groups or pairs. Moreover, teachers sometimes or almost rarely let their students choose what to do. A few teachers apply other techniques in their mixed-level classes. This discussion results in the following outcome - there is still the need to raise teachers' awareness of the techniques to deal with students of different needs in class.
\end{abstract}

UDC Classification: 376, DOI: https://doi.org/10.12955/pss.v2.206

Keywords: mixed-levels; mixed-abilities; differentiated instruction; learning types; student-centered approaches.

\section{Introduction}

It would be great to teach a class with students having the same linguistic levels, abilities, learning styles, or preferences but we all know that very often this perfect word is simply imaginary, since teachers have to deal with classes having students of different needs. In Georgia, teachers face this problem both at schools and universities. At universities, students are grouped or placed according to their performance in the national entrance exams or, later, according to standardized placement tests. However, as many courses are not based on the same skills which are tested by the standardized tests, the levels where students are placed do not accurately match with their abilities, concerning the skill focus of the courses they take.

The situation at schools is far more challenging, as students' foreign language level completely depends on the age and correspondingly the grade they are in. The fact that students' levels vary considerably in language courses is not new, and that it causes some problems for both teachers and students is not new either. Taking into account the common teacher-centered or the one-book-fits-all approach, where the teacher is forced to focus on the middle level, many students at the top or bottom end of the language scale are left dissatisfied or demotivated. However, it is a common reality, if once students are placed into a certain class they are regarded as being at much the same linguistic level in their foreign language. And the one-book-fits-all approach is often adopted in the classroom, where all students are required to work at the same pace and complete tasks of the same difficulty.

"In both general education and language teaching, a focus on individual differences has been a recurring theme in the last 30 years, as seen in such movements or approaches as Individualized Instruction, Autonomous Learning, Learner Training, and Learner Strategies" (Richards \& Rogers 2001). Although the movement in which students are viewed as possessing individual learning needs started a long time ago, teachers and students are still struggling with the same problem. Richards and Rogers focus on Multiple Intelligences, the term that is also related to specific learning preferences but from a bit of a different angle. The traditional approach, based on which teachers tend to polarize a class into two parts: stronger, high ability, fast learners and the opposite weaker, low ability, slow learners, needs to be abandoned. Many authors working in this field advise teachers to become more student-oriented by providing comprehensible input, using a variety of teaching methods and materials, providing interesting and challenging tasks in a student- focused - environment. It has been seen as the best or the only way to deal with medium to large groups of second language learners. However, we know, although students are divided into different linguistic levels, many courses, especially with medium to large classes, contain students with different language styles, strengths, and weaknesses. They develop

\footnotetext{
${ }^{1}$ Batumi Shota Rustaveli State University, ivditidiasamidze@gmail.com

${ }^{2}$ Batumi Shota Rustaveli State University, lalitavadze@gmail.com

${ }^{3}$ Batumi Shota Rustaveli State University, natia.katamadze@gmail.com
} 
at different rates and they have different preferences. Thus, teachers have to accept the reality and start dealing with the challenging situation. Experts agree that one book, set of materials, or pace will never be completely suitable for every single student in the class. Learning styles, preferences, as well as different skills and abilities, can vary greatly within the class. Teachers should work on a more studentoriented and differentiated approach that provides a more level-appropriate, and motivating learning experience for all students in the class regardless of their level.

The responsibilities taken by teachers are far more challenging than one can imagine since they have to act as an information giver and as a facilitator. The two categories fall into several sub-categories. For example, a teacher as an information giver could take the role of explainer, demonstrator, organizer and instruction giver, controller, and route planner. The teacher as a facilitator could take the role of a guide, monitor, support system, feedback giver, and counselor (Hadfield, J. \& Hadfield, C, 2008). Therefore, the load teachers carry is heavy, they should be ready to reflect on classroom practices, to realize what problem-solving approach will work best when there are some difficulties identified, and finally try out a range of approaches to meet individual needs and get students to achieve their potential best. The teacher becomes a facilitator and not someone who just stands at the front of the classroom. The focus is on what students learn and not what teachers teach (Bremner, 2008).

After experiencing the problems outlined above, teachers should decide on a more flexible and studentcentered approach to language teaching and learning, which should be adopted. It could be how to create an environment that includes both classroom management and material design techniques so that students are enabled to study and produce language at their own pace and according to their individual needs. Hence, the process leads to final goals that are appropriate and satisfying for both teachers and students (Wilkinson, 2012).

The present paper aims at 1 . discussing diverse scholarly approaches to the problem and 2. conducting a survey whose goal is to disclose: a. whether teachers are aware of the techniques and b. what is the frequency of their use while teaching mixed-level classes.

\section{Different approaches to multi-level classes}

According to Bill Bowler and Sue Parminter (Richards \& Renandya, 2008), a simple equation: text level of challenge + task level of support $=$ student success. could represent students' abilities to read or listen well enough. A simple assignment,- designed to follow a long complex text, makes reading or listening comprehension easier for weaker students. On the other hand, an assignment might turn into a more challenging one with a shorter text. Taking into account these principles, they have come up with two different ways of designing reading and listening activities that could fit mixed-level classes. These tasks are called tiered tasks and bias tasks.

Tiered tasks vary according to students' abilities (strong/ midlevel and weak). It might be a matching task to be used when dealing with reading for weak students; with midlevel students multiple-choice questions with more than one correct answer and with strong students open questions to make the task more challenging for them. This way tiered tasks produce the same or similar results for all students (Richards \& Renandya, 2008).

They also believe that with the reading activities students could be allowed to choose the tasks themselves according to the level of support they need (a lot of/ some/no support). Initially, when students are not used to this principle, they may risk choosing the most difficult tasks, or vice versa, stay on the safe side and choose easier tasks. However, when students get used to selecting tasks themselves with the teacher's guidance, they gradually start choosing some realistic ones for their level, something they can cope with. It could be a challenging task that boosts their motivation (Richards \& Renandya, 2008).

Scrivener (2013) also suggests letting students choose their own tasks, work speeds, outcomes, etc. rather than imposing your own plans and expectations, hence allowing students to make their own decisions.

Bias tasks produce complementary results. For example, weaker students write answers to the questions whenever stronger students write questions for the given answers. Because the answers to these two tasks are complementary, it would be better to economize time by using student-student (strong+ weak) feedback instead of giving post activity feedback with the whole class. The teacher should monitor and 
check in case some strong students have come up with alternative questions of their own (Richards \& Renandya, 2008).

Bill Bowler and Sue Parminter (Richards \& Renandya, 2008) call them tiered and bias tasks while Jim Scrivener calls them differentiated work. We have already discussed these tasks- to assign different work to different people. The same approach called differentiated instruction is discussed by A. V. Kelly. Kelly assumes that one must find the "most efficient means of leading individual pupils towards our educational objectives" when trying to imply equality in education for diverse groups through mixed-ability teaching or differentiated instruction (Kelly, 1974).

Jim Scrivener also offers one more option while teaching mixed-level classes - dividing the class (separating the different levels out). Teachers might decide and try out the following techniques: 1 . Make short-term pairs or threes for a single task, deliberately mixing stronger and weaker students together. 2. Long-term pairs, threes, or groups for a month or half term, each including one stronger student who is openly given the task of guiding and supporting the other students. 3. Divide the class into two halves or more subdivisions if it is useful for some parts of each lesson. Prepare tasks at two or more different levels. While one part is working independently on a task, the teacher can work with the other half. Later, the teacher can swap over, giving a task to students in that group while moving over to teach and work with the other. Split and- combine workflow is the technique where the whole class starts work on something together, and later in the lesson, different subsections of the class separate off to do different work, maybe the same tasks at a different pace, or tasks that have a similar focus, but with different language levels. These groups later come back together and so on (Scrivener, 2013).

\section{Methods}

To find out how often teachers refer to different techniques a survey was carried out. The teachers working both at higher educational institutions and secondary schools represent the survey target population. Overall, 30 teachers were questioned. A questionnaire designed for the teachers includes a set of 4 key questions. The questions focused on how often (often/sometimes/never) differentiated work/ dividing class/ letting students choose the task / other techniques are used. The respondents were asked to fill in the paper questionnaire. Eventually, the data was collected and analyzed by the authors.

\section{Results}

The analysis is based on the data collected through the survey. The following table shows the percentage of the teachers and the techniques applied according to their frequency.

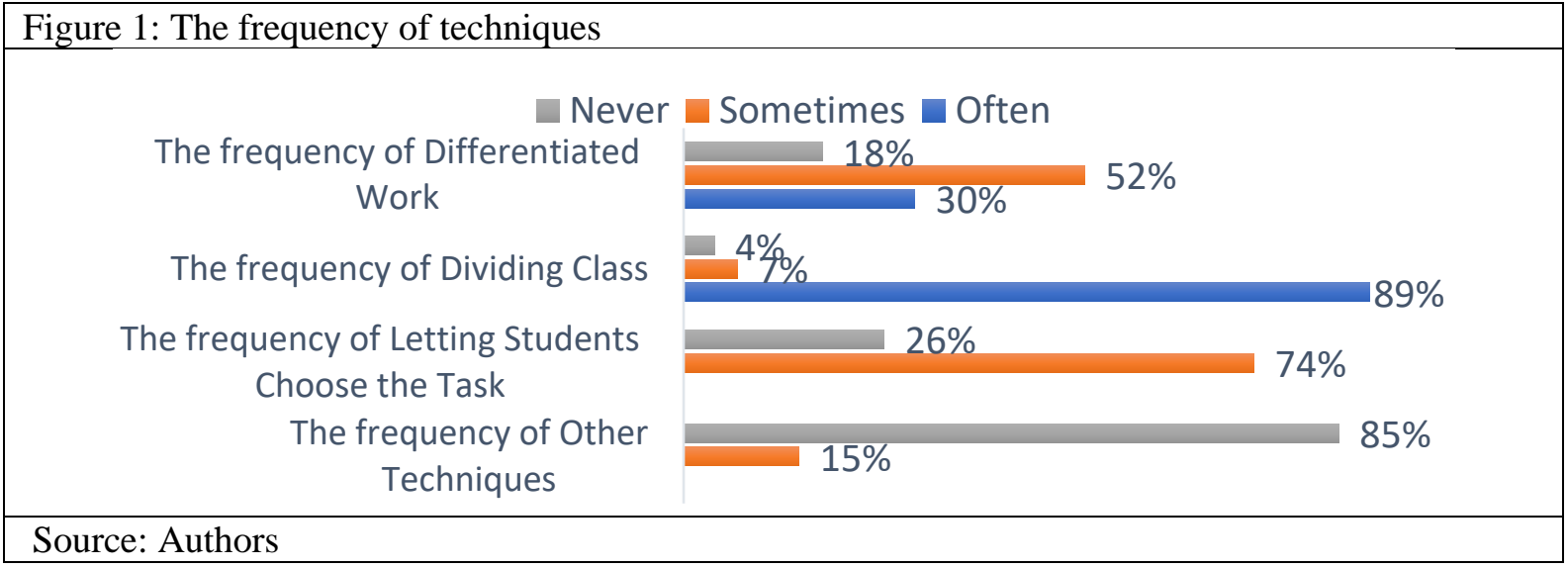

The first part of the table deals with how often differentiated work is used by teachers. The largest number of teachers sometimes use this technique. They make up 52 percent. The second largest number of teachers often use it. They make up 30 percent. The least number of teachers never use it, and they make up 18 percent. Hence, we can say that differentiated work is likely used by 30 percent of all, highlighting that much more than half either sometimes or never use it.

The second part of the table shows how often dividing a class is used by teachers. The number increases rapidly with often and it makes up 89 percent. As opposed to it, the number decreases with sometimes and never. The teachers sometimes using this technique make up 7 percent and quite surprisingly there are still teachers who never use it and they make up 4 percent of all. Therefore, we can say that the largest number of teachers use this technique in their classes. 
The third part of the table is about how often letting students choose the task is used by teachers. The largest number of teachers sometimes use this technique. They make up 74 percent. The number of teachers never using it is three times as small as those who use it sometimes. They make up 26 percent. Compared to this frequency there is no one who often uses it. Hence, we can say that majority of teachers sometimes try to use letting students choose the task in classes.

The fourth part of the table shows how often other techniques are used by teachers. The largest number of teachers never use them. They make up 85 percent. The least number of teachers sometimes use them. They make up 15 percent. And there is no one who is willing to often use them. Therefore, we can say that majority of teachers avoid using other techniques.

Overall, the survey shows that differentiated work is not as popular as dividing the class. The latter is claimed to be the most preferable of all. Letting students choose the task is more popular than using other techniques among the teachers.

\section{Discussion and implication}

It was very satisfying to discover that almost all the teachers were aware of these approaches. Based on the data collected we can conclude that differentiated work requires much more and thorough thinking and preparation on the part of a teacher, which becomes quite time-consuming at times (Figure 1). Therefore, teachers try to deal with mixed-level classes using mostly class division techniques into groups or pairs (Figure 1). The third part reveals that teachers sometimes or almost rarely let their students choose what to do (Figure 1), which could be explained due to the fact that they are afraid of possible risks of unfair distribution. Most importantly, it could be for the following reason- stronger students might choose weaker tasks and vice versa. The final part shows that just a few teachers apply other techniques in their multi-level classes (Figure 1). A great variety of other techniques are available on different sites. For instance, British Council offers a wide range of resources related to the same topic (Rees, 2003). However, the result demonstrated by the final chart could probably be due to the fact that teachers are not quite aware of them.

\section{Conclusion}

This discussion results in the following outcome - there is still the need to raise the awareness of teachers' towards techniques used to deal with students of different needs in class. An acknowledgment of many educational problems in the areas of differentiated work leads us to realize that teachers have to be trained so they may welcome, initiate and thus control change. Although teachers have to follow the national curriculum at schools and accepted syllabuses at universities, they are not free to deviate much from them, and weaker and stronger students both have to cover the same topics. We base our discussion on several points. Individualization in multi-level classes requires that educational objectives remain the same, but that content materials differ to meet individual needs. Teachers will need to adapt instructional materials to individual learning. All this will result in hugely improved dynamics and an improved pace of the class as well as increased motivation, enjoyment, and interaction.

\section{References}

Bremner, S. (2008). Teaching a mixed ability class. Retrieved from https://www.languageswithoutlimits.co.uk/resources/sbremner.pdf

Hadfield, J., Hadfield, C. (2008) Introduction to teaching English, Oxford University press. (148-149)

Kelly, V. (1974) Teaching mixed ability classes: an individualized approach. London: Harper \& Row,. 125Jack C. (Review) 96-97

Rees, G. (2003) Teaching mixed-ability classes 1. British Council. Retrieved from https://www.teachingenglish.org.uk/article/teaching-mixed-ability-classes-1

Rees, G.(2003) Teaching mixed-ability classes 2. British Council. Retrieved from. https://www.teachingenglish.org.uk/article/teaching-mixed-ability-classes-2

Richards, J. C., Renandya, W. A. (2008) Methodology in Language Teaching An Anthology of Current Practice, Cambridge university Press. (59-63) Retrieved from

https://viancep2012.files.wordpress.com/2011/12/methodology_in_language_teaching_2002_scanned.pdf

Richards, J. C., Theodore, S. Rogers. (2001) Approaches and Methods in Language Teaching. Second Edition. Cambridge University Press. 115-123

Scrivener, J. (2013) Classroom management Techniques. Cambridge University Press. 88-107

Wilkinson, D. (2012). Student-centered activities in mixed-level classes. In A. Stewart \& N. Sonda (Eds.), JALT2011

Conference Proceedings. Tokyo: JALT. Retrieved from https://jalt-publications.org/files/pdf-article/jalt2011-061.pdf 